\title{
진정요법의 현황
}

\author{
박 철 수* | 가톨릭대학교 의과대학 서울성모병원 마취통증의학과
}

\section{The current state of sedation outside the operating room}

\section{Chul Soo Park, MD*}

Department of Anesthesiology and Pain Medicine, Seoul St. Mary's Hospital, The Catholic University of Korea, College of Medicine, Seoul, Korea

*Corresponding author: Chul Soo Park, E-mail:p6c8s I7@catholic.ac.kr

Received December 12, 2012 · Accepted January 5, 2013

\begin{abstract}
$T$ he demand for sedation outside of the operating room for diagnostic or therapeutic procedures has recently been dramatically increasing. The Joint Commission International $(\mathrm{JCl})$ is pressing domestic hospitals trying to obtain $\mathrm{JCl}$ certification to accept its sedation policies. This article aimed to investigate recent trends in sedation and suggest desirable directions for safe and high-quality sedation. The most active areas in research are procedural sedation, sedation in the intensive care unit (ICU), and pediatric sedation. Patient safety and performance of procedures without complications are the most important goals during sedation. According to the $\mathrm{JCl}$ regulation, noninvasive blood pressure, electrocardiography, pulse oximetry and capnography are the basic requirements, and sedation personnel should be separate from those who perform the procedure. Careful preprocedural assessment and tight intra-procedural monitoring for airway obstruction are critical in procedural sedation. Many merits of dexmedetomidine in procedural sedation have been reported despite its hemodynamic risks. Daily intermittent interruption is the main trend in ICU sedation providing better outcomes for mechanically ventilated patients. Analgosedation in the ICU is initial analgesia starting with remifentanil and later adding sedatives if required. Individual readjustment of the dosage using a sedation scoring system is a key requirement for successful results in ICU sedation. Ketofol, mixture of ketamine and propofol, has recently become popular for painful pediatric procedures. Pediatric sedation (especially for those $\leq 3$ years) with computed tomography or magnetic resonance imaging examination has a greater risk of hypoxia, but pediatric sedation experts are lacking. In conclusion, there is an urgent need for the nationwide establishment of standard sedation regulation, and securing or training sedation specialists.
\end{abstract}

Keywords: Sedation; Ambulatory surgery; Joint Commission on Accreditation

\section{서 론}

지엉요서

정요법은 전신마취 수준까지 요구되지 않는 수술실 밖 에서 시행되는 의학적 진단 또는 치료적 시술들의 원
활한 진행을 위해 필요하다. 요즘 환자들은 통증을 느끼지 않는 상태라 하더라도 시술 중 조금의 불안 및 불편감도 꺼려 하기에 진정을 요구하는 경향이 크다. 특히, 최근에는 의료 기관의 서비스 평가가 활발한 사회적 분위기여서, 환자의 의

(C) Korean Medical Association

This is an Open Access article distributed under the terms of the Creative Commons Attribution Non-Commercial License (http://creativecommons. org/licenses/by-nc/3.0) which permits unrestricted non-commercial use, distribution, and reproduction in any medium, provided the original work is properly cited. 
료서비스 만족도에 큰 영향을 가진 진정 및 진통요법 대한 관 심은 점점 더 커져가고 있다.

진정요법이란 심폐기능을 유지하면서 어느 정도의 의식 상태 저하를 통해 환자가 불쾌한 의료적 시술을 견뎌낼 수 있게끔 약물을 투여하는 기술을 일컫는다. 이상적인 진정이 란 환자가 시술 중 두려움 없이 안락하고 협조적인 상태를 보이는 것을 말한다. 진정의 수준은 다양한 척도들(sedation scale)에 의해 평가 및 점수화되는데, 1974년에 고안된 Ramsay Sedation Scale이 그 원형이라고 할 수 있다[1]. 1999년 미국마취과학회(American Society of Anesthesiologists, ASA)에서는 진정의 수준을 간략히 최소진정(minimal sedation), 중등도진정(moderate sedation), 깊은진정 (deep sedation), 전신마취(general anesthesia)의 4단계 로 구분하고 있다. 과도한 진정은 호흡정지, 혈압감소 및 심 정지와 같은 치명적인 부작용이 생길 수도 있어 세심한 모니 터링을 필요로 한다.

다양한 의료의 영역들에서 진정요법은 쓰이지만, 가장 연 구가 활발하고 이용도가 높은 세 가지 진정 관련 분야를 중 심으로 알아보도록 하겠다. 첫 번째는 진단적 내시경 검사, 미용성형 시술 등과 같은 비수술실 시술진정(procedural sedation), 둘째로 중환자실에서의 진정, 마지막으로 비수 술실에서의 소아들을 위한 진정이다. 이들 분야에서 진정요 법의 최근 동향을 파악하여 보다 안전하고 높은 수준의 진정 요법의 정착에 도움이 되고자 한다.

\section{비수술실 시술진정}

2009년 이후 우리나라를 찾는 의료관광객 수가 크게 늘 어 2011년에는 11만 명이 넘었고, 2015년에는 30만 명 시대 를 열 것으로 생각된다. 특히, 지난해 보건복지부의 조사에 따르면 최근 5년간 미용시술을 포함한 의료관광을 목적으로 한국을 방문하는 외국인이 두 배 이상 증가했다고 보고하고 있다. 또한, 매스미디어를 통한 전문적 건강상식의 범람, 병 원들의 최근 주력 홍보상품인 건강검진 패키지 등을 통해 진 단적 내시경검사도 꾸준하게 늘고 있다. 미국의 의료통계에 따르면 통원수술(ambulatory surgery)의 55\%는 수술실이
아닌 시술자의 진료실(office based anesthesia)에서 시행 된다고 보고하였다[2]. 최소침습적 술기의 발전과 마취/진 정을 안전하게 제공할 수 있는 능력의 진보에 기인해 비수술 실 시술은 점점 더 늘어가는 추세이다. 이와 더불어 의료공 급자 측면에서 진료만족도 제고의 수단으로 시술진정에 대 한 수요 또한 증가하고 있다.

수술실 밖의 시술진정 시 환자 안전을 위해 요구되는 핵 심적인 인자들은 다음과 같다. 1) 적절한 모니터링; 2) 직원 채용, 기구/장비, 응급상황 시 반응에 관련된 방침들; 3) 유 사 시 신속히 작동할 수 있는 마취보조 장비; 4) 시술 및 회복 공간의 적절성; 5) 공기교환, 전기적인 안전기준 및 공학적 인 요건을 충족하는 의료가스관 설비(piping of medical gases) [3]. 시술진정에 필요한 모니터링은 ASA에서 제시한 기본적 마취를 위한 모니터링(심전도, 비침습적혈압, 산소 포화도, 호기말이산화탄소, 체온)과 동일한 항목들을 필요 로 한다[4]. 호기말이산화탄소 감시는 일반적으로 깊은진정 을 요하는 환자들에게 해당하며, 심폐질환자들에게는 최소 진정의 경우에도 실시되어야 한다. 비수술실 시술진정 시 환자 손상의 빈도는 수술실내에서 발생하는 것보다 오히려 더 심각한 수준으로 보고된다[5]. 그 중 부적절한 산소/환기 화(oxygenation/ventilation)가 진정 관련 의료소송의 가 장 많은 원인이었으며, 소송 중 $62 \%$ 는 시술 중 신중한 모니 터링을 통해 예방이 가능했었던 것들로 분류되었다.

다음과 같은 경우들은 환자의 안전을 위해 시술진정에 적 합하지 않다[3]. 1) 다량의 혈액손실 가능성; 2) 6시간 이상의 긴 수술; 3) 중환자들; 4) 특수한 마취나 술기를 요하는 경우 (심폐우회술, 흥부, 대뇌 수술); 5) 시술 후 환자관리에 대한 대비가 제한적인 경우이다. 시술 전 진정을 담당할 요원들 은 계획된 시술과정, $\mathrm{ASA}$ 신체분류, 기도상태, 과거병력 및 마취 과거력, 알레르기, 금식, 이학적 검사 소견 등에 관한 꼼꼼한 점검을 해야 한다. 특히, 기도이상(difficult airway), 병적비만, 중등도 이상의 수면무호흡증, 만성폐쇄성폐질환, 말기기관부전 및 6개월 이내 심근/대뇌 경색 등에 관해서는 철저한 조사가 이뤄져야 하겠다.

시술진정에는 propofol, midazolam, ketamine, dexmedetomidine과 같은 약물이 쓰이고, 진통 보완에는 단기 
작용 아편유사제인 fentanyl, remifentanil, sufentanil 등이 이용된다. 마취가스 배출장치가 없는 환경에서는 전정맥내 기법(total intravenous technique)으로 조금씩 약 용량을 증가시키는 적정화(titration)를 통해 목표 진정수준에 이르 게 하는 게 안전한 진정의 방법이다. 1985 년 처음으로 내시 경 시술에 관한 보고 이래로, propofol은 환자의 만족감, 회 복시간 및 경제적인 측면에서 장점이 있어 지금까지 가장 널 리 시술진정에 쓰여온 약물이다. 하지만, 과잉진정에 따르는 문제들이 심각해 시술 전 신중한 환자선정 및 시술과 독립적 인 숙련된 감시인력을 필요성이 꾸준히 제시되어 왔다[6]. 2010년도에 진정/진통작용을 가지지만 호흡억제 부작용이 상대적으로 적은 alpha-2 작용제인 dexmedetomidine이 국내에 소개되어 많은 관심을 받고 있다. Dexmedetomidine은 1999년에 미국 식품의약청(Food and Drug Administration) 승인 후 중환자실에서 사용 및 연구가 활발했지 만, 현재는 다른 영역에서도 그 사용의 범위가 넓혀지고 있 다. 안면 미용성형 분야의 한 조사에서, dexmedetomidine 투여 군은 다른 진정제들이 투약된 군에 비해 탈산소화 (oxygen desaturation) 사건들의 발생률이 훨씬 낮았고, 시 술 중 다른 진정/진통제의 요구량 또한 적었으며, 시술 후 항 구토제의 처방도 현저하게 적은 것으로 조사되었다[7]. 아편 유사제 중 가장 짧은 상황민감성반감기(context sensitive half-life)를 가진 remifentanil은 대장내시경을 위한 깊은진 정 시 propofol과의 병용요법으로 쓰이는데, 목표농도조절 (target controlled infusion, TCI) 펌프를 이용한 지속투여 방식이 수동적인 주사(manual injection) 방식보다 호흡억 제의 빈도가 적은 것으로 조사되었다[8]. Paracetamol과 cyclooxygenase-2 억제제를 포함한 비스테로이드소염제, 스테로이드 등도 시술 전 병용 또는 보조 투여 시 아편유사 제 관련 부작용을 줄이면서 통증을 효과적으로 덜어줄 수 있 는 것으로 알려져 있다[9].

시술 후 환자들은 적절한 장비가 구비된 회복공간에서 지 속적으로 관리되어야 하고, 기존의 회복실 퇴실기준들을 만 족했을 때 퇴원하게 된다[10]. 시술 후 오심과 구토(postperative nausea and vomiting, PONV)도 퇴원을 지연시키 며 진료의 만족도를 저하시키는 중요한 요인들 중 하나이
다. PONV의 예방을 위해선 아편유사제를 피하는 것이 좋지 만, 위험성이 있는 환자들을 위해서는 dexamethasone, scopolamine, 5-hydroxytryptamine antagonists 등의 항 구토제의 예방적 사용도 고려해야 한다.

\section{중환자실에서의 진정}

기계환기를 받고 있는 중환자들의 불편감을 덜어주기 위 해서 진정/진통은 당연시 받아들여져 왔고, 통계에 따르면 $42-72 \%$ 의 중환자실 환자들에서 처방이 된다[11]. $80 \%$ 이 상의 중환자들은 필요 시 morphine, fentanyl을 보완하지 만, benzodiazepine 혹은 propofol을 기반으로 한 지속적 진정-수면요법을 받아왔다[12]. 이 방식은 기계환기로부터의 이탈지연 및 중환자실 체류기간의 연장과 같은 심각한 부작용 과 연관되는 것으로 알려졌다[13,14]. 요즘은 remifentanil 을 우선적으로 주고, 필요 시 propofol을 추가하며, 그리고 최소진정을 목표로 매일 주기적으로 일정시간 동안 진정을 중단하는 시간을 삽입시키는 진통진정(analgosedation) 개 념이 중환자실 진정요법의 대세로 자리잡고 있다. 이는 약 제의 투여량을 감소시켜 기계환기 이탈과 관련된 부작용을 줄이는데 긍정적인 결과를 보이고 있다[15].

중환자실 진정의 목표는 환자들의 불편감, 불안, 초조 (agitation)를 감소시키고, 기계환기기와의 이상동조(dysynchrony)로 인한 호흡량 및 산소소모량의 증가를 막아 환자의 안정 및 안전을 도모하는 것이다. 논란이 있기는 하 지만 기존에 중환자실에서 널리 쓰이던 benzodiazepine, morphine, fentany은 중환자실에서의 사망률, 체류기간, 퇴원 후 인지기능 손상의 예측인자인 섬망(delirium)의 발 생원인이 될 수 있다는 몇몇 보고들이 있다[16,17]. 진정을 받는 모든 중환자들은 개인별 임상상황에 맞는 진정의 목표 를 가지며, 주기적 평가를 통해 진정의 정도가 재조정되어야 한다. Ramsay Sedation Scale, Riker Sedation Agitation Score [18], Richmond Agitation-Sedation Scale [19] 등과 같은 다면적 접근법의 척도들로 진정수준은 평가된다. 최근 에는 각성의 정도를 수치화하는 4 채널 뇌파 감시장치인 bispectral index (BIS)가 많이 쓰이는데, 2002년 Society 
of Critical Care Medicine Sedation Guideline은 중환자 에게서 BIS 모니터링은 그 유용도를 제고할 필요가 있다고 하였다. BIS는 근이완제를 투여 받는 환자들에게 다른 진정 척도들이 사용될 수 없는 경우에 보조적 진정 감시장치로서 그 활용성이 한정된다[20].

중환자들을 위한 이상적인 진정제의 조건은 경제적이고, 혈류역학적 효과 및 호흡억제가 경미해야 하고, 약물 상호작 용이 없고 활성 대사산물의 생성이 적어야 하며, 신체기관에 독성이 적으면서 짧은 상황민감성반감기를 가져 장기기능 과 무관한 대사기전을 가져야 한다. 불행하게 이와 모두 일 치하는 진정제를 찾기는 쉽지 않지만, GABA 작용제인 propofol, benzodiazepines (midazolam, lorazepam)이 가장 많이 사용되어왔고, alpha-2 작용제인 dexmedetomidine 이 최근에 증가 추세에 있다. Propofol은 아편유사제 시도 후 일차적으로 선택(first line)되는 진정제로서 흔히 $\mathrm{TCI}$ 를 통한 지속주입 방식으로 투여된다. Propofol은 약효의 발현 이 신속하고 지속주입 후 중지 시 빠른 시간 내 종료되며, 조 절이 용이하고, 수시로 신경학적 검사가 가능한 장점 때문에 중환자실에서 가장 흔하게 쓰인다. 하지만 저혈압, 고콜레 스테롤혈증, 췌장염, 호흡억제, 프로포폴주입증후군 (propofol infusion syndrome) [21]과 같은 합병증이 생길 수 있어 신중한 모니터링이 필요하다. 앞에서 언급했듯이 중 환자실에서 dexmedetomidine 사용과 관련된 임상 연구가 매우 활발하다. Midazolam과 비교 시 dexmedetomidine 은 기계환기 시간, 중환자실 체류 기간, 사망률에서는 차이 가 없었지만, 섬망(delirium)의 발생률에 있어서는 두드러 지게 낮았다[22]. 최근에 propofol과 비교한 연구에서는, 환 자와의 상호작용에 대한 visual analogue scale 평가에서 dexmedetomidine이 더 우수한 결과를 보였다[23].

\section{비수술실 소아 진정}

방사선학적 검사, 심장도관삽입(cardiac catheterization), 소아 중환자실, 응급실과 같은 수술실 밖에서 소아를 대상으로 한 진정이 늘고 있다. 소아 진정 관련 연구도 최근 10 년간 약 2.5 배 가까이 증가되는 추세를 보이고 있다. 과거
소아 진정은 해당과 주치의들이 자체적으로 해결했었지만, 최근에는 병원 차원에서 마취통증과 책임 하에 진정 전문인 력을 배치하고 체계적인 소아 진정의 알고리즘을 개발하려 고 노력하는 중이다. 소아 진정에는 ketamine, etomidate, midazolam, propofol, dexmedetomidine와 같은 정맥마 취제들과 흡입마취제인 아산화질소(nitrous oxide)가 흔히 포함된다. 항불안 작용 및 진통효과를 가진 아산화질소는 약 80\% 이상의 소아 진정에서 ketamine이나 국소마취제 사용 시 보조적으로 사용된다[24]. 저산소증의 위험성이 있 지만 임상의 많은 경우에서 산소공급 없이 단독으로 쓰이는 것으로 알려져 있다[25]. Propofol은 가장 많이 쓰이는 진정 제인데, 요즘은 ketamine의 사용이 늘어 이 두 약물의 혼합 제제인 'Ketofol'의 형태로 통증을 유발할 수 있는 소아 시술 시 많이 쓰인다[26]. Propofol의 소아에서의 안전성에 대해 서는 많은 이견들이 있지만, 다양한 임상경험 및 진정훈련을 거친 의료인들에는 propofol로 인한 부작용 발생은 그다지 큰 문제가 되지 않는 것으로 결론 짓고 있다.

컴퓨터단층촬영(computed tomography, CT)이나 자기 공명영상(magnetic resonance imaging, MRI) 촬영과 같 은 방사선학적 검사 시 환아의 안전과 높은 질의 영상을 얻 기 위해서 진정이 필요하다. CT나 MRI 촬영을 받는 대부분 의 환아들은 신경계 질환, 혈관기형, 소아 종양과 같은 선천 적인 질병을 갖는 경우가 많고, 간질, 지능저하도 흔히 동반 되어 진정 또는 마취의 필요성이 크다고 할 수 있다. 방사선 촬영 시 소아 진정의 목표는 환아의 안전 확보, 불편감 및 통 증 최소화, 불안과 정신적 충격 최소화, 기억상실 최대화, 영 상촬영을 위한 움직임 조절, 안전한 퇴원을 위한 완전한 회복 이다. 금식, 정맥관 확보, 생체활력징후 모니터링은 전신마취 와 똑같이 준비하여야 하며, 진정을 실시하는 자는 기구나 소 아 기도를 다루는데 있어 많은 경험을 가진 자이어야 한다. 일반적으로 장애를 가진 환아에서 진정 중 저산소증 발생위 험도는 정상인의 세 배가 넘는 것으로 알려져 있다[27]. 그러 므로, 전신마취와 동일한 시설을 구비하고 기도확보 및 응급 구명을 위한 장비들을 즉각적으로 사용할 수 있도록 꼼꼼한 사전점검을 마친 상태에서 진정을 시작해야 한다.

3세 이상, 몸무게 $10 \mathrm{~kg}$ 이상의 특별한 기도이상이 없는 
소아들은 진정이 전신마취의 대안으로 추천될지도 모르지만, 3 세 이하 영아, 주요 동반질환을 가진 경우에는 시술 중 기도 폐쇄의 위험성이 커 전신마취를 선택해야 한다. 기도폐쇄는 복합적 진정약제의 사용, 부적절한 시술 전 환자평가, 시술 중 철저하지 않은 모니터링, 약물부작용 등에 기인한다[28]. 소 아 진정요법 중 심장 관련 합병증은 거의 없으나 기도폐쇄가 빨리 해결되지 않을 경우에 유발될 수도 있다.

소아 진정에 있어 공급자의 숙련도와 경험은 무엇보다 중 요한 항목이다. 일부 대형 대학병원들이 마취통증과의 책임 으로 소아 진정을 위탁하고 있으나, 소아 진정 전문인력 및 필수적 진정 기본장비들은 절대적으로 부족한 상황이기에 환아를 담당하는 해당과의 적극적인 지원을 포함한 국가적 인 차원의 소아 진정체계의 설립이 시급하다고 볼 수 있다.

\section{Joint Commission International하에서의 진정요법}

최근 국내 대형 대학병원들은 국제적 의료평가기관으로 부터 인증을 획득하려고 공급되는 의료서비스의 구조 및 관 행들의 국제적 표준화를 추진하고 있다. 미국 내 비영리 의 료평가기관인 Joint Commission는 1997년부터 Joint Commission International (JCI)이란 분과를 통해 국제적 표준의료평가 확산을 목적으로 그 영역을 확장하고 있다. 현재, 국내의 많은 병원들이 JCI 인증을 시도하고 있기에, 진 정에 관련한 JCI의 규정들을 살펴 볼 필요성이 있다.

먼저, JCI 규정에서는 진정을 실시하는 자들에 대한 엄격 한 자격규정을 요구하고 있다. 꼭 마취과의사일 필요는 없 지만, 진정에 참여하는 자는 환자시술과는 반드시 독립적이 어야 한다. 깊은진정일 경우에는 보다 더 높은 기준의 훈련 과 자격을 요구하고 있다. 기본적으로 advanced cardiac life support 자격증 획득을 요구하고 있으며, 진정 전후 환 자에 대한 전문적 평가나 진정 중 약물투여 및 모니터링, 합 병증이 생겼을 때 적절하고 신속한 대처(삽관 및 후두마스 크 삽입 등)가 가능할 수 있도록 일정한 교육기간 및 자격을 필요로 하고 있다. 의료기관에 대해서도 진정을 실시하는 자들에 대한 체계적 교육 및 평가시스템, 각종 진정관련 기
록들(진정 전 평가서, 동의서 및 진정 중 기록, 회복실 퇴실 기준)의 철저한 구비와 표준화된 진정관련 시설 완비를 지 시하고 있다. 진정 후 환자만족도, 안전도, 효율성과 같은 환 자결과에 대해서도 quality improvement and patient safety 부분을 통해 진정요법의 질 관리를 지시하고 있는 상 황이다[29].

국가적 차원의 진정에 관한 표준지표는 아직 마련되어 있 지 않고, JCI 인증평가를 추진하는 의료기관 별로 통일되지 않은 진정방침만 있는 게 우리의 현실이다. 진정요법에 대 한 수요 증대와 의료의 세계화 흐름에 발맞춰, 진정요법의 표준화된 가이드라인이 어느 때 보다 절실한 시점이다.

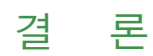

진단적 검사나 미용목적 또는 최소침습적 시술이 증가하 고 있고, 이에 따른 의료서비스 질과 관련해 진정 및 진통의 요구는 점점 증가하고 있다. 하지만, 전문 진정인력의 부족, 진정제에 대한 이해 부족, 환자 모니터링의 소홀은 항시 의 료사고의 소지를 가지고 있다. 비수술실 시술 중 진정에 대 한 합리적인 보상수가의 책정과 소아 진정을 포함한 진정관 련 독립적 부서의 설립, 국가적인 표준 진정지침의 마련은 진정과 관련해 우리가 앞으로 해결해야 할 과제라고 할 수 있겠다.

핵심용어: 진정, 통원수술, 의료기관평가

\section{REFERENCES}

1. Ramsay MA, Savege TM, Simpson BR, Goodwin R. Controlled sedation with alphaxalone-alphadolone. Br Med J 1974; 2:656-659

2. Pino RM. The nature of anesthesia and procedural sedation outside of the operating room. Curr Opin Anaesthesiol 2007; 20:347-351.

3. Eichhorn V, Henzler D, Murphy MF. Standardizing care and monitoring for anesthesia or procedural sedation delivered outside the operating room. Curr Opin Anaesthesiol 2010;23: 494-499.

4. American Society of Anesthesiologists. Standards for basic anesthetic monitoring [Internet]. American Society of Anesthesiologists; 2011. Available from: http://www.asahq.org/ForMembers/ /media/For\%20Members/documents/Standards\%20 
Guidelines\%20Stmts/Basic\%20Anesthetic\%20Monitoring\%20 2011.ashx.

5. Metzner J, Posner KL, Domino KB. The risk and safety of anesthesia at remote locations: the US closed claims analysis. Curr Opin Anaesthesiol 2009;22:502-508.

6. Vargo JJ, Cohen LB, Rex DK, Kwo PY. Position statement: nonanesthesiologist administration of propofol for $\mathrm{Gl}$ endoscopy. Gastrointest Endosc 2009;70:1053-1059.

7. Taghinia AH, Shapiro FE, Slavin SA. Dexmedetomidine in aesthetic facial surgery: improving anesthetic safety and efficacy. Plast Reconstr Surg 2008;121:269-276.

8. Moerman AT, Herregods LL, De Vos MM, Mortier EP, Struys MM. Manual versus target-controlled infusion remifentanil administration in spontaneously breathing patients. Anesth Analg 2009;108:828-834.

9. Hval K, Thagaard KS, Schlichting E, Raeder J. The prolonged postoperative analgesic effect when dexamethasone is added to a nonsteroidal anti-inflammatory drug (rofecoxib) before breast surgery. Anesth Analg 2007;105:481-486.

10. Awad IT, Chung F. Factors affecting recovery and discharge following ambulatory surgery. Can J Anaesth 2006;53:858872.

11. Salgado DR, Favory R, Goulart M, Brimioulle S, Vincent JL. Toward less sedation in the intensive care unit: a prospective observational study. J Crit Care 2011;26:113-121.

12. Rhoney DH, Murry KR. National survey of the use of sedating drugs, neuromuscular blocking agents, and reversal agents in the intensive care unit. J Intensive Care Med 2003;18:139145.

13. Bauer TM, Ritz R, Haberthur C, Ha HR, Hunkeler W, Sleight AJ, Scollo-Lavizzari G, Haefeli WE. Prolonged sedation due to accumulation of conjugated metabolites of midazolam. Lancet 1995;346:145-147.

14. Nelsen JL, Haas CE, Habtemariam B, Kaufman DC, Partridge A, Welle S, Forrest A. A prospective evaluation of propylene glycol clearance and accumulation during continuous-infusion lorazepam in critically ill patients. J Intensive Care Med 2008; 23:184-194.

15. Kress JP, Pohlman AS, O'Connor MF, Hall JB. Daily interruption of sedative infusions in critically ill patients undergoing mechanical ventilation. N Engl J Med 2000;342:1471-1477.

16. Pandharipande P, Cotton BA, Shintani A, Thompson J, Pun BT, Morris JA Jr, Dittus R, Ely EW. Prevalence and risk factors for development of delirium in surgical and trauma intensive care unit patients. JTrauma 2008;65:34-41.

17. Pandharipande PP, Pun BT, Herr DL, Maze M, Girard TD, Miller RR, Shintani AK, Thompson JL, Jackson JC, Deppen SA, Stiles RA, Dittus RS, Bernard GR, Ely EW. Effect of sedation with dexmedetomidine vs lorazepam on acute brain dysfunction in mechanically ventilated patients: the MENDS randomized controlled trial. JAMA 2007;298:2644-2653.

18. Riker RR, Picard JT, Fraser GL. Prospective evaluation of the Sedation-Agitation Scale for adult critically ill patients. Crit Care Med 1999;27:1325-1329.

19. Ely EW, Truman B, Shintani A, Thomason JW, Wheeler AP, Gordon S, Francis J, Speroff T, Gautam S, Margolin R, Sessler CN, Dittus RS, Bernard GR. Monitoring sedation status over time in ICU patients: reliability and validity of the Richmond Agitation-Sedation Scale (RASS). JAMA 2003;289:2983-2991.

20. LeBlanc JM, Dasta JF, Kane-Gill SL. Role of the bispectral index in sedation monitoring in the ICU. Ann Pharmacother 2006;40:490-500.

21. Corbett SM, Montoya ID, Moore FA. Propofol-related infusion syndrome in intensive care patients. Pharmacotherapy 2008; 28:250-258.

22. Riker RR, Shehabi Y, Bokesch PM, Ceraso D, Wisemandle W, Koura F, Whitten P, Margolis BD, Byrne DW, Ely EW, Rocha MG; SEDCOM (Safety and Efficacy of Dexmedetomidine Compared With Midazolam) Study Group. Dexmedetomidine vs midazolam for sedation of critically ill patients: a randomized trial. JAMA 2009;301:489-499.

23. Jakob SM, Ruokonen E, Grounds RM, Sarapohja T, Garratt C, Pocock SJ, Bratty JR, Takala J; Dexmedetomidine for LongTerm Sedation Investigators. Dexmedetomidine vs midazolam or propofol for sedation during prolonged mechanical ventilation: two randomized controlled trials. JAMA 2012; 307:1151-1160.

24. Babl FE, Belousoff J, Deasy C, Hopper S, Theophilos T. Paediatric procedural sedation based on nitrous oxide and ketamine: sedation registry data from Australia. Emerg Med J 2010;27:607-612.

25. Shavit I, Leder M, Cohen DM. Sedation provider practice variation: a survey analysis of pediatric emergency subspecialists and fellows. Pediatr Emerg Care 2010;26:742-747.

26. Andolfatto G, Willman E. A prospective case series of pediatric procedural sedation and analgesia in the emergency department using single-syringe ketamine-propofol combination (ketofol). Acad Emerg Med 2010;17:194-201.

27. Kannikeswaran N, Mahajan PV, Sethuraman U, Groebe A, Chen $X$. Sedation medication received and adverse events related to sedation for brain MRI in children with and without developmental disabilities. Paediatr Anaesth 2009;19:250-256.

28. Cravero JP, Blike GT, Beach M, Gallagher SM, Hertzog JH, Havidich JE, Gelman B; Pediatric Sedation Research Consortium. Incidence and nature of adverse events during pediatric sedation/anesthesia for procedures outside the operating room: report from the Pediatric Sedation Research Consortium. Pediatrics 2006;118:1087-1096.

29. Kweon TD. Sedation under JCl standard. Korean J Anesthesiol 2011;61:190-194. 


\section{(2) Peer Reviewers' Commentary}

진정요법은 많은 진료 현장에서 시행되고 있으며, 최근 의학의 발달과 사회변화에 따라서 불안 및 불편을 피하고자 하는 환자의 요구 증대 및 의료진의 적합한 진료를 위하여 그 필요성이 증가하고 있다. 이러한 진정요법은 적절하게 시행되었 을 경우 환자의 안락하고 협조적인 상태에서 진료의 원활한 진행을 이룰 수 있으며, 환자와 의료진의 만족도를 증가시킬 수 있다. 그러나 진정요법은 환자의 안전성을 최우선으로 고려해야 하며 과도한 진정요법으로 인한 부적절한 산소/환기화 및 심혈관계 억제 예방 및 부작용의 최소화가 필요하다. 따라서 이를 위해서는 진정요법에 대한 숙련되고 경험 있는 의료 진과 장비들이 요구되고 있는 상황이다. 이러한 상황에서 본 논문은 진정요법이 특히 많이 요구되는 비수술적 시술진정. 중환자실에서의 진정, 그리고 비수술실 소아진정에 대하여 간결하게 요약하여 소개하고 있다. 따라서 이 내용들은 실제 진료 현장에서 안전하고 높은 수준의 진정요법의 사용에 도움이 될 것으로 기대한다.

[정리: 편집위원회] 